\title{
Genera nova Hemipterorum
}

descripsit Dr. 0. M. Reuter, Helsingforsiensis.

II.

\section{Ectmetacanthus}

novum genus Reduviidarum (Acanthaspidinorum) ex Africa.

Corpus oblongo-ovatum; capite, prosterno, coxis femoribusque omnibus inermibus; capite ante oculos producto, a latere viso fortiter decurvo, pone oculos impressione subrecta. transversali instructo, longe constricto, parte intraoculari parte anteriore partis postocularis angustiore, parte anteoculari medio ad basin antennarum dentibus duobus minutis, jugis brevibus, subito abbreviatis, bucculis elevatis et articulum primum rostri a gula distantem reddentibus; ocellis minutis; oculis rotundatis, solum medium genarum attingentibus; antennis prope oculorum apicem interne insertis, articulo primo apicem partis anteocularis haud vel vix attingente, secundo primo vix duplo longiore; pronoto ruguloso, lobo antico valde convexo, fortiter sculpturato, inermi, postico (formae brachypterae) depresso, sub-horizontali, margine basali supra scutellum truncato, brevi, valde transverso, sexangulari, angulis lateralibus extrorsum spinosoproductis, disco ad basin tuberculis duobus latis obtuse rotundatis; scutello mox ante medium in spinam longam, oblique surgentem, leviter decurvatam, subparallelam et apice excisam constricto, marginibus lateralibus antice tuberculo obsoletiore instructis; hemelytris abbreviatis; processu prosterni haud recurvo; pectore ruguloso nec granulato; metasterno ventreque basi carinatis; pedibus posticis sat distantibus, tibiis femoribus distincte longioribus, tarsis articulis duobus primis aeque longis, tertio secundo longiore; tibiis anterioribus fossa spongiosa instructis.

Generi Acanthaspis A. et S. affinis, spina insigni scutelli ejusque margine laterali antice tuberculo instructo mox distinctus. A reliquis generibus autem divisionis 21 (30) Stali in Enumer. Hemipt. IV, p. 65, ventre basi carinato divergens.

\section{E. annulipes n. sp.}

Diagn. Fusco-niger vel niger, capite, thorace pedibusque longe fusco-pilosis, abdominis dorso glabro, ventre brevius pallidopiloso, nitido; capite superne a basi usque ad bases antennarum, marginibus tamen partis postocularis exceptis, pronoto vittis, maculis angulisque spinosis lateralibus lobi postici, spina scutelli. 
hemelytris, vitta media utrinque abbreviata clavi lineolaque media corii exceptis, segmentorum omnium connexivi macula transversali apicali, maculis externis coxarum, annulis duobus femorum et tibiarum, tarsis, apice vel tarsis posticis apicibus articulorum omnium exceptis, antennisque articulis duobus primis testaceis, harum articulo primo dimidio apicali secundoque apice fuscis; membrana sericeo-nigra, medio fusco-conspersa. Long. $\sigma^{7} 6^{3}{ }_{4} \mathrm{Mm}$.

Habitat in Chinchoxo (Mus. Berol.).

Descr. Caput fusco-nigrum, longe fusco-pilosum, superne a basi usque ad antennarum bases testaceum, impressione transversali postoculari lateribusque partis postocularis fusco-nigris; parte postoculari pronoti lobo antico longitudine subaequali, parte anteoculari a latere visa postoculari fere aeque longa. Rostrum crassum. piceo-nigrum, articulis duobus primis longitudine subaequalibus. Antennae longe pallido-pubescentes et adhuc pilis longioribus fuscis pilosae, articulis duobus primis testaceis, primo dimidio apicali et secundo apice fuscis. Pronotum fusco-nigrum, longe fusco-pilosum. rugosum, lobo antico macula media anteriore vittisque quatuor posticis in lobum posticum continuatis, intermediis medio incurvatis, lateralibus strictura interruptis et in angulos laterales lobi postici extrorsum productis; tubereulis lobi postici fuscis. Scutellum fusco-nigrum, spina superne testaceum, nigro-marginatum. Hemelytra $\left(\sigma^{7}\right)$ abbreviata, medium segmenti quarti dorsalis attingentia. testacea, clavo vitta media utrinque abbreviata corioque lineola media nigris; membrana corii longitudine, sericeo-nigra, medio nonnihil fusco-conspurcata. Pectus fusco-nigrum, maculis externis ad coxas obscure testaceis. Dorsum abdominis nigrum, opaculum. transversim subtiliter strigosum, segmento sexto tamen dimidio apicali transversim fortius rugoso; suturis postice crenulatis. Connexivum nigrum, segmentis omnibus macula apicali transversa testacea. Venter nitidum, pilosum, segmento maris genitali ultimo ventrali paulo longiore. Pedes nigri, nitidi, longe fusco-pilosi. femoribus annulo latiore ante medium alioque angusto prope apicem. tibiis annulis duobus, posteriore latiore mox infra medium, tarsisque flavo-testaceis, horum anteriorum articulo ultimo apice, posticorum omnibus apice nigris, unguiculis testaceis; fossa spongiosa tibiarum anticarum tertiam apicalem partem nonnihil superante. 


\section{$2 \mathrm{BHL}$ Biodiversity Heritage Library}

Reuter, Odo Morannal. 1882. "Genera nova Hemipterorum." Wiener entomologische Zeitung 1, 111-112. https://doi.org/10.5962/bhl.part.11149.

View This Item Online: https://www.biodiversitylibrary.org/item/42649

DOI: https://doi.org/10.5962/bhl.part.11149

Permalink: https://www.biodiversitylibrary.org/partpdf/11149

\section{Holding Institution}

Smithsonian Libraries

\section{Sponsored by}

Smithsonian

\section{Copyright \& Reuse}

Copyright Status: NOT_IN_COPYRIGHT

This document was created from content at the Biodiversity Heritage Library, the world's largest open access digital library for biodiversity literature and archives. Visit BHL at https://www.biodiversitylibrary.org. 